Article

\title{
Language Provision in Education: A View from Scotland
}

\author{
Róisín McKelvey \\ School of Literatures, Languages and Cultures, University of Edinburgh, Edinburgh, EH8 9LH, UK; \\ E-Mail: r.r.mckelvey@sms.ed.ac.uk
}

Submitted: 20 August 2017 | Accepted: 16 October 2017 | Published: 22 December 2017

\begin{abstract}
A tension between mobility and inclusion can be seen in public sector attempts to respond to the increasingly multilingual nature of the Scottish population. Increased mobility has contributed to greater linguistic diversity, which has led to growing demand for multilingual public services. Legal instruments and education policy in Scotland provide a promising framework in terms of promoting language learning and multilingualism, but implementation is not always successful and responding to linguistic diversity among pupils is beset with challenges. This article will consider some of these challenges, both practical and attitudinal, reflecting on language teaching in Scotland and on issues raised during interviews with officials from the English as an additional language (EAL) services in Edinburgh and Glasgow. Language teaching often does not take into account the linguistic diversity present-despite the opportunity for a more inclusive approach offered by Scottish Government strategy - and this risks reinforcing negative beliefs about significant allochthonous languages in Scotland. In these circumstances, meeting the linguistic needs of increasingly multilingual school populations in an inclusive way is a challenging task.
\end{abstract}

\section{Keywords}

education; English; inclusion; language; mobility; multilingualism; school; Scotland; teaching

\section{Issue}

This article is part of the issue "Multilingualism and Social Inclusion", edited by László Marácz (University of Amsterdam, The Netherlands/Gumilyov Eurasian National University, Kazakhstan) and Silvia Adamo (University of Copenhagen, Denmark).

(C) 2017 by the author; licensee Cogitatio (Lisbon, Portugal). This article is licensed under a Creative Commons Attribution 4.0 International License (CC BY).

\section{Introduction}

The United Kingdom's (UK) position as one of Europe's "largest immigrant-receiving countries" (Baldi \& Wallace Goodman, 2015, p. 1153) has led to greater cultural and linguistic diversity and therefore a rise in demand for multilingual public services. One area in which multilingual support is necessary is education: schools are facing the challenge of responding to the practical educational needs of pupils who require support with their English, with limited resources. Meeting these needs in an inclusive way that, ideally, fosters positive attitudes towards linguistic diversity and multilingualism, is one facet of this challenge.

This is an example of the connection between mobility and inclusion; alongside the practical aspect of English as an additional language (EAL) services, they are also significant in terms of socio-economic inclusion. As part of the Mobility and Inclusion in Multilingual Europe (MIME) project, François Grin has developed a concept referred to as the trade-off model, with which to analyse the compatibility of different policy goals (Grin, 2017; Grin, Marácz, Pokorn, \& Kraus, 2014). This model holds that society often tries to attain multiple goals, some of which correspond and others that diverge from one another, and a trade-off often occurs between those goals which diverge. The interaction between two such goals, and any trade-off that results, is not static or inevitable, but rather dynamic and influenced by numerous factors, one of which is policy, because policy that increases or facilitates one may hinder the other (Grin, 2017; Grin et al., 2014). Well-designed policy, therefore, can alleviate tension between seemingly conflicting goals. The trade-off model was specifically developed to analyse the goals of promoting intra-European Union (EU) mobility and social inclusion (Grin, 2017; Grin et al., 2014). According 
to the trade-off model, although mobility and inclusion are not necessarily incompatible, a tension can exist between them.

There are a number of legal instruments and policies that could be discussed, but the focus in this article will be on the legal and policy norms established byand the nature of the implementation of-the following: the Council of Europe's European Convention on Human Rights, the UK's Human Rights Act 1998, the European Council Directive 77/486/EEC and the Scottish Government's $1+2$ Language Strategy. The position of language in the UK's Equality Act 2010 and the Code of Practice for the Education (Additional Support for Learning) (Scotland) Act 2004 will also be highlighted.

For the purposes of this article, this trade-off will be discussed in relation to education in Scotland, considering the tension between increasingly multilingual school populations and inclusive teaching. Legal and policy frameworks will be considered, and issues raised during several interviews carried out with members of staff from the EAL services, which work with schools and professionals to support pupils who are learning English, in Edinburgh and Glasgow will be discussed, highlighting practical and attitudinal challenges faced in service delivery.

These interviews are part of my research into the practical reality of local service delivery and the challenges faced in meeting service demand and legal and policy obligations. The EAL services are supported by the respective local authorities (the City of Edinburgh Council and Glasgow City Council) and similar themes emerged in the interviews with each service. Limited resources and increased service demand influence strategy choices, as services develop new ways of meeting the demand, such as a greater role for peripatetic teachers, and capacity building and training within schools. Alongside such practical challenges and responses, two key issues raised during interviews were the continued importance of challenging attitudes that approach linguistic diversity among pupils as a problem and of working with families and professionals to counter misconceptions and negative beliefs about the use of languages other than English at home, to encourage intergenerational transmission. The challenges highlighted during these interviews suggest that education services in Edinburgh and Glasgow still have work to do in adapting to the greater diversity resulting from increased mobility in an inclusive manner.

This is also the case in other aspects of the Scottish education system, such as the limited implementation of the Scottish Government's 1+2 Language Strategy: many schools continue to prioritise European languages such as French and German, while languages with significant speaker communities, such as Polish, are rarely included in the mainstream education system (Hancock, $2014,2017)$. As a result, community-run complementary schools are a significant source of cultural and linguistic education for other allochthonous ${ }^{1}$ languages and receive little state support (Hancock, 2014, 2017; Wang, 2011). Although there are opportunities for greater inclusion in the Scottish education system in terms of legal and policy frameworks, both practical and attitudinal constraints remain and there is a lack of truly diverse provision.

\section{Legal Obligations and the Place of Language: European, UK and Scottish Instruments}

When considering approaches to multilingualism and inclusion at the local level, such as in education services, it is important to note the legal and policy norms that affect such approaches and the number of levels at which such norms are established: supranational, national and local. The actual implementation of such norms may vary for a variety of reasons, including access to resources, political contexts and lack of understanding of legal or policy obligations, and the practical applications of a select few will be explored below.

For several relevant legal instruments, implementation is at present in a potentially precarious position in the UK due to political circumstances. It should be noted that with the UK's decision to withdraw from the EU, key conventions and legal instruments relevant to equalities, rights and linguistic diversity will no longer be binding in the UK. They nevertheless remain relevant now. In addition, there is a degree of uncertainty about the position of the Council of Europe's European Convention on Human Rights (European Convention), and subsequently the UK's Human Rights Act 1998, because there has been discussion in the UK political sphere about withdrawing from the former-an instrument that has some significance in terms of language-and about replacing the $\mathrm{Hu}$ man Rights Act 1998. Given this political context, it is unclear what their future will be in the UK. At present, both legal instruments are still binding, and so they will be considered here.

The European Convention includes a general prohibition of discrimination, in addition to a prohibition of any discrimination that threatens the rights established within it, specifically referring in both cases to discrimination based on a number of grounds, including language, national origin and association with a national minority (Council of Europe, 2010). The Human Rights

\footnotetext{
${ }_{1}^{1}$ The terms 'allochthonous' and 'autochthonous' language(s) will be used in the article. 'Allochthonous' refers to languages that are not historically associated with Scotland, while 'autochthonous' refers to languages that are, such as Scottish Gaelic. Having originated in the field of geology (see Bekers, 2009), 'allochthonous' carries a more neutral connotation than other commonly used terms like 'immigrant', 'migrant', 'community' or 'heritage' language(s), which are often politicised and used to refer to particular languages or language communities, rather than to all allochthonous languages. There can still be problematic discourse surrounding the term 'allochthonous' because it means 'from elsewhere' and could arguably be alienating and pejorative-and also inaccurate, given that many members of these speaker communities are UK-born or naturalised citizens (McLeod, 2008). Additionally, the term has different connotations in different contexts (see Bekers, 2009, regarding Belgium and the Netherlands, for example). There may be no truly neutral term, but 'allochthonous' is preferred here as more neutral than other options.
} 
Act 1998 incorporated the European Convention into UK law and includes the particular legal rights established by it, in addition to the prohibition of discrimination on language grounds that would prevent the enjoyment of these rights. It does not, however, include the general prohibition of discrimination found in the European Convention, because this prohibition is set out by Optional Protocol No. 12 (Council of Europe, 2010), which the UK (along with numerous other states) has neither signed nor ratified (Council of Europe, 2017). The Human Rights Act 1998 does require public authorities to act in accordance with the rights set out by the European Convention, however, which therefore does establish a prohibition of discrimination on the grounds of language, national origin and association with a national minority, among others, for public authorities in the UK.

It is worth noting an EU legal instrument that requires member states to provide a certain degree of language teaching and support. The European Council Directive 77/486/EEC (Council of the European Union, 1977) establishes an obligation to provide the children of EU workers with free tuition in the official language (or one of the official languages) of the host state (Council of the European Union, 1977). On a practical level, competence in the dominant language of a host country is a useful skill and can facilitate access to the economic, cultural, social and educational opportunities available in the host state: "[e]vidence from all countries of immigration makes it clear that mastery of the national language(s) is fundamental to economic success" (Hansen, 2003, pp. 34-35). This can come at the expense of allochthonous languages, however; often the linguistic pattern for immigrants is that by the third generation full linguistic assimilation has occurred (Dunbar, 2007).

Directive 77/486/EEC does state that member states should "promote" teaching the children of EU nationals the "mother tongue" of their country of origin (Council of the European Union, 1977, Article 3). Since Directive $77 / 486 / E E C$, aimed to promote cross-border mobility within the EU, it was thought that the teaching of a mother tongue of the state of origin would ease return to that state, should an intra-EU migrant and his or her family wish to do so. These obligations apply only to the children of EU citizens, of course, and impose a lesser commitment concerning the teaching of European allochthonous languages, in comparison to specifically requiring free tuition in one of the host state's official languages (Council of the European Union, 1977). Nevertheless, it does establish a legal framework that requires a certain degree of multilingual education to facilitate integration in the host state and in the country of origin, respectively.

Despite the establishment of these obligations by Directive $77 / 486 / E E C$, there appears to be limited implementation of the instrument and fulfilment of the obligations it sets out. A 2008 EU Green Paper questioned the influence that Directive 77/486/EEC could have on the development of national-level policy, describing its im- plementation as "patchy" and "difficult" (European Commission, 2008, pp. 4, 13). Member states have developed their own policy approaches to the teaching of their official language(s), with seemingly little influence from Directive 77/486/EEC, while the more flexible requirement concerning allochthonous languages has had only "some patchy impact" (European Commission, 2008, p. 14). The increased intra-EU mobility following the 2004 and 2007 accessions was noted, as was the fact that Directive 77/486/EEC establishes obligations only regarding EU citizens; it does not address the educational rights or needs of children from outside of the EU (European Commission, 2008). This limits its scope and its application in relation to the demographic reality of many EU states (Atger, 2009; European Commission, 2009).

When considering the legal and policy context in which Scottish public services are developed, it is important to note the particular political structure that influences this, because it is not only shaped by supranational and UK-level national frameworks, but also by legislation and policy established by the Scottish Government and Parliament. The devolution agreement, which determined which areas would be under its control and which would remain under the control of the Westminster Parliament and the UK Government, is pertinent because several relevant policy areas, such as immigration, asylum and equal opportunities, are 'reserved matters' and thus the responsibility of the Westminster Parliament. However, other areas, including education, health and social services and law and order, are 'devolved matters', legislated on by the Scottish Parliament. This legal structure provides an interesting dynamic regarding mobility and inclusion in Scotland since, while immigration and asylum issues-mobility-are controlled at the UK level by the Westminster Parliament, many aspects of social policy that are related to inclusion are determined at the Scottish level.

Official EU principles establish linguistic diversity and multiculturalism in Europe as a cultural wealth to be safeguarded and promoted (Council of the European Union, 2008). At the UK level, however, although equalities legislation affords protection from discrimination, language remains relatively overlooked in domestic legislation. The Equality Act 2010 (Chapter 15, Part 2, Chapter 1) identifies nine "protected characteristics"; language, however, is not one of them, which means that it is not directly protected under this piece of antidiscrimination legislation. It is possible that language could be indirectly protected under the "race" category, because this includes "ethnic or national origins" (Equality Act 2010, Chapter 15, Part 2, Chapter 1), but there is no specific reference to or inclusion of language in the legislation. Equal opportunities is a reserved matter under the Scottish devolution agreement, and so the Equality Act 2010 applies in Scotland as well.

In Scotland, language issues are specifically engaged by the Code of Practice for the Education (Additional Support for Learning) (Scotland) Act 2004; the Act itself does 
not list specific additional support needs, but the Code of Practice does list EAL as one of these needs, and identifies in-class EAL provision as an example of how education services can fulfil their legislative obligations (Scottish Executive, 2010).

There are therefore a number of legal and policy norms connected to language that apply to education in Scotland, but the obligations established are in several cases somewhat vague, or not explicitly applied to language issues. Although Optional Protocol No. 12 of the European Convention does not apply in the UK, and so the Human Rights Act 1998 does not include its general prohibition of discrimination on the grounds of language, this prohibition does have a place because UK public authorities are required to uphold the rights protected by the European Convention. On the other hand, the Equality Act 2010, which is a key piece of legislation used by Scottish local authorities in service planning and delivery, does not explicitly protect against discrimination on the grounds of language.

Directive 77/486/EEC establishes obligations to provide free tuition in a state language and to promote the teaching of allochthonous European languages, which of course places (vague, in the latter case) obligations on Scottish schools, but only regarding EU citizens. This is nevertheless relevant to speakers of significant European languages such as Polish. Challenging inadequate provision as discrimination on the grounds of language, however, would be difficult, because Directive 77/486/EEC establishes only a vague obligation to promote allochthonous European language education, rather than to provide it. Scottish Government guidance on the Education (Additional Support for Learning) (Scotland) Act 2004 explicitly refers to EAL provision (Scottish Executive, 2010) and these services do form an important part of local education services, but of course this is relevant only to pupils who are not proficient in English; for others, the Scottish Government's 1+2 Language Strategy is significant, but its implementation has so far been limited. Since the Strategy encourages an in- clusive approach but does not require provision for specific languages, schools are relatively free to make their own language teaching choices.

The legal instruments relevant to Scottish schools therefore establish certain (sometimes limited) obligations regarding provision for specific pupils-EU citizens and EAL pupils, for example-but language remains relatively overlooked in UK legislation, and there is a lack of specific requirements that apply to all pupils.

\section{The Linguistic Composition of Scotland and Language Choices in Education}

As shown in Table 1, in the 2011 Scottish Census Polish speakers outnumbered those of other European allochthonous languages and those of non-European languages that had previously been among the most significant speaker groups, such as Urdu, Punjabi, Gujarati, Bengali and Chinese languages (National Records of Scotland [NRS], 2015). There is a practical need to respond to the increasingly multilingual nature of Scottish schools, and to provide linguistic support for those pupils who need it. In 2016, approximately $5.75 \%(39,342)$ of Scottish pupils had English as an additional language (Scottish Government, 2016a), which is a significant increase from $3.38 \%(22,740)$ in 2010 , despite the much smaller increase in total pupil numbers (Scottish Government, 2010). In 2016, the most common languages spoken at home other than English were Polish, Urdu, Scots, Punjabi and Arabic (Scottish Government, 2016a). Although the focus here is on allochthonous languages, Scottish Gaelic language education should not be entirely overlooked. In 2016, approximately $0.6 \%(3,892)$ of Scottish school pupils attended Gaelic-medium education (Gaelic was the language spoken at home for approximately $0.08 \%$, or 522 , of pupils), while for approximately $0.04 \%$ (268) of pupils Gaelic was the only subject taught through the language and approximately $0.88 \%(6,055)$ of pupils attended Gaelic learner classes (Scottish Government, 2016a).

Table 1. 2011 Scottish Census: Language spoken at home (NRS, 2015).

\begin{tabular}{lr}
\hline Language spoken at home & Scotland \\
\hline All usual residents aged 3+ & $5,118,223$ \\
People who speak only English at home & $4,740,547$ \\
Arabic & 9,097 \\
Chinese & 27,381 \\
French & 14,623 \\
German & 11,317 \\
Italian & 8,252 \\
Polish & 54,186 \\
Punjabi & 23,150 \\
Spanish & 10,556 \\
Urdu & 23,394 \\
\hline
\end{tabular}

* Includes Mandarin, Cantonese, Min Nan Chinese and 'unspecified' Chinese.

Note: Table 1 shows a selection of allochthonous languages with significant speaker numbers in the 2011 Scottish Census. 
In 2012, the Scottish Government launched its Language Strategy, which included accepting recommendations to introduce the teaching of two languages at different stages during primary school education and to encourage the teaching of Scottish Gaelic and both European and non-European allochthonous languages-with specific reference to the home languages ${ }^{2}$ of pupils and "local circumstances and priorities" (Scottish Government, 2012, Annex A, p. 18). The Scottish Government also accepted the recommendation to develop links with language communities, cultural organisations, local authorities and schools in order to "derive maximum benefit" from allochthonous language communities (Scottish Government, 2012, p. 24), although no specific connection was drawn between these links and allochthonous language teaching.

There has been some inclusion of non-European allochthonous languages in Scottish secondary education provision, but allochthonous language teaching remains relatively limited. The Scottish Qualifications Authority (SQA) has developed secondary education qualifications in Cantonese, French, Gaelic (Learners), German, Italian, Mandarin (Simplified), Mandarin (Traditional), Spanish and Urdu. Considering Directive 77/486/EEC, it is worth noting that in Scotland, secondary school provision for European languages other than French, German and Spanish is limited, and a "tilting" towards such "popular" European languages, particularly French, is common (Hancock, 2014, p. 174). This suggests that the Strategy's implementation is often not inclusive and not in line with the linguistic composition of schools or communities; while it provides a framework that would allow for an inclusive approach that responds to the diversity present, in many cases this has not been realised.

The lack of provision in Scottish education for Polish is interesting, considering Directive 77/486/EEC establishes an obligation to promote the teaching of European allochthonous languages so that the children of EU migrants are able to integrate linguistically in their/their parents' countries of origin. Although this obligation remains relatively flexible and does not impose any specifics on EU member states, it is noteworthy that the significant Polish-speaking community has received so little provision in the Scottish education system; particularly given the Scottish Government's reference to pupils' home languages (Scottish Government, 2012) regarding language selection under its $1+2$ Language Strategy. This highlights the limited implementation of Directive 77/486/EEC and the fact that the European languages generally taught in Scottish schools do not reflect the demographic reality of Scotland. In addition to not fulfilling the EU's aim to facilitate reintegration in the country of origin, the relative exclusion of a significant language such as Polish from mainstream education could hinder inclusion for its speaker community in Scotland, reinforcing negative beliefs about multilingualism and suggesting a low status for even the most commonly spoken allochthonous languages. Additionally, even for children who do not return to their/their parents' countries of origin, a lack of education in their families' allochthonous languages could threaten intergenerational transmission and communication within communities and families. There a trade-off between mobility and inclusion: intra-EU mobility has led to the establishment of a significant Polish-speaking community but, in responding to this, the linguistic needs of this community have not been approached in an inclusive way within the Scottish education system.

Complementary schools are a significant source of linguistic and cultural education for allochthonous language communities, providing a space outside of mainstream education-usually after school or at the weekend-that can facilitate the intergenerational transmission of these languages (Wang, 2011). Complementary schools are community-based language schools that often rely on parent volunteers, or "parent teachers", to teach the languages in question (Wang, 2011, pp. 2-3). This can be problematic because many parent teachers do not have teaching qualifications or experience, and many may not be familiar with pedagogy in the UK (Wang, 2011). Hancock (2014, p. 178) does argue, however, that complementary schools afford communities the chance to retain ownership of their linguistic and cultural education and that they can provide "safe spaces" for the negotiation of identities and linguistic development.

There is a range of approaches to organising complementary schools: the use of mainstream school premises or religious centres, affiliation with consulates or with "heritage" countries, or organisation by families or communities (Hancock, 2017). Complementary schools rely on financial support from consulates, restricted grants from local authorities and the campaigning of community members to raise funds; they are therefore limited by a lack of resources, and provision remains "patchy" (Hancock, 2014, p. 177). There has been an overall decrease in provision by complementary schools, as well as a lack of provision for asylum seekers and refugees (Hancock, 2017). Furthermore, Hancock's (2017) research found that many complementary schools were not aware of the Scottish Government's 1+2 Language Strategy and did not have any links with local authorities or with mainstream schools to further this awareness or to provide allochthonous language learning activities.

\section{Linguistic Support and Language Learning in Scottish Education, and the Challenges Encountered}

\subsection{Practical Challenges}

During interviews with officials from the EAL services in Edinburgh and Glasgow, certain themes emerged that illustrated challenges faced by public service providers in fulfilling obligations. There is often a lack of understand-

\footnotetext{
2 'Home language(s)' refers to allochthonous or autochthonous languages spoken at home.
} 
ing of legal frameworks and equalities obligations-such as the provision of EAL support under the Additional Support for Learning Act 2004-and, where such knowledge exists, there are often insufficient resources to fully implement them, particularly as service demand increases (S. Scott, EAL teacher, personal communication, $7 \mathrm{Au}$ gust 2017). There are also challenges faced in disseminating this information within schools: EAL services provide training-including information about legal and policy instruments, and the value of linguistic diversitybut there is a need, often unmet, for that training and knowledge to be passed on within schools (S. Scott, EAL teacher, personal communication, 7 August 2017). Recent developments in EAL provision, however, have included a focus on capacity building within schools, both inside and outside the classroom (EAL official, personal communication, 17 August 2017). In Edinburgh, for example, there are pilot projects in place in a small number of schools, trialling intensified work with teachers to evaluate and improve teaching practices around linguistic diversity and EAL pupils (EAL official, personal communication, 17 August 2017). Such strategies may alleviate the pressure on services due to increased demand: expanding knowledge of good practice and challenging misconceptions can improve teaching practices and pupils' experiences.

Resource constraints are a challenge, as UK EAL services operate with reduced staff numbers at a time when service demand is growing (Educational Institute of Scotland [EIS], 2014; National Association for Language Development in the Curriculum [NALDIC], 2011, 2014). The EAL interviews discussed strategy changes-including a greater reliance on peripatetic teachers and training within schools-and restructurings of services in order to meet increasing service demand without proportional resource increases (S. Scott, EAL teacher, personal communication, 7 August 2017; M. Walker, Head of Glasgow's EAL Service, personal communication, 15 May 2017). The resulting increase in numbers of pupils and schools on staff caseloads worsens time constraints and creates difficulties in providing adequate support for schools and for individual pupils; this has a negative effect on pupils' experiences (NALDIC, 2011; S. Scott, EAL teacher, personal communication, 7 August 2017).

\subsection{Attitudinal Challenges}

Constructions of national identity and group membership are increasingly connected to language: "belonging and the discursive construction of individual and collective national identities are becoming linked more and more to language policies" (Wodak \& Boukala, 2015, p. 254), and the ideal of proficiency in English tends to be encouraged in the UK: "At government level, policymaking still seeks linguistic conformity for allochthonous populations" (Wright, 2016, p. 246). Although there are practical benefits to proficiency in the dominant language (Hansen, 2003), focus on the English language and neg- ative attitudes towards linguistic diversity can hinder the intergenerational transmission of allochthonous languages and therefore lessen multilingualism in the UK.

A significant aspect of responding to the practical needs of pupils while facilitating inclusion within classrooms and school communities is fostering positive attitudes towards multilingualism and the allochthonous languages spoken by pupils; this was an issue highlighted during several interviews with officials from EAL services. The Director of Bilingualism Matters, Professor Antonella Sorace (personal communication, 2 May 2017), emphasised the importance of encouraging schools to recognise and promote their pupils' home languages and of encouraging intergenerational transmission within families. This is particularly important due to the culture of monolingualism in the UK (McLeod, 2008). Hancock (2014, p. 174) described the "prevailing monolingual mentality" present in Scotland as "both a fallacy and short sighted" and argued that it hinders Scottish pupils economically, culturally and educationally.

While approximately $70 \%$ of respondents to a recent Scottish Social Attitudes Survey reported speaking a language other than English, only 26\% of these respondents were able to speak as much as a few simple sentences or partial conversations and only $11 \%$ could participate in most or all of a conversation in a language other than English (Scottish Government, 2016b). There were also indications that social attitudes towards the teaching of different languages echoed the seeming prioritisation of "popular" European allochthonous languages (Hancock, 2014, p. 174) in the Scottish education system. The majority of respondents (89\%) stated that learning a language other than English from the age of five was "very" or "quite" important, but $63 \%$ selected Western European languages (particularly French and Spanish) as the "most appropriate" choices (Scottish Government, 2016b, p. 3). If language teaching is to be diversified and adapted to better correspond to the linguistic composition of Scotland, it seems likely that work will need to be done to promote the value of non-Western European languages and non-European languages more widely.

Within education itself, the limited application of the Scottish Government's 1+2 strategy might negatively affect pupils; the lack of provision for or promotion of a range of allochthonous languages may impact inclusion within the school community and the value attributed to allochthonous languages, which for many pupils are their home languages. If even the most significant allochthonous languages are not included in the Scottish education system-even under a strategy that explicitly promotes language learning - this suggests a low status for these languages and reinforces negative perceptions of them. This lack of mainstream provision and the reliance on community-led initiatives for allochthonous language teaching discourages intergenerational transmission (A. Sorace, Director of Bilingualism Matters, personal communication, 10 June 2013). 
EAL services in Edinburgh and Glasgow have found that it is not uncommon for families to claim an inaccurate level of English language proficiency, through fear that their child's school enrolment or attainment may be at risk if they admit to low proficiency and to another home language (EAL official, personal communication, 17 August 2017; M. Walker, Head of Glasgow's EAL Service, personal communication, 15 May 2017). In many countries parents are advised (by teachers and professionals) that their children will be disadvantaged if an allochthonous language is spoken at home in place of, or in addition to, the dominant language (Akoğlu \& Yağmur, 2016; Place \& Hoff, 2011). This misconception was raised in all of my interviews; the EAL services in both Edinburgh and Glasgow, and the research organisation Bilingualism Matters, often encounter it. If parents believe this message, it can lead to "impoverished input" (A. Sorace, Director of Bilingualism Matters, personal communication, 10 June 2013), or "a restricted code" (Akoğlu \& Yağmur, 2016, p. 718), in the dominant language. Such input is less useful to language acquisition than input from native speakers and can also hinder parent-child communication and the intergenerational transmission of the allochthonous home language (Akoğlu \& Yağmur, 2016; Place \& Hoff, 2011).

\section{Conclusions}

There are legal frameworks and strategies in place that theoretically offer inclusive approaches to linguistic diversity and positive developments for language provision, but in reality there appears to be a failure to include significant allochthonous languages such as Polish in the Scottish education system. Allochthonous language communities remain largely responsible for their own language teaching, with little cooperation with either local authorities or mainstream schools.

Education services in Scotland must respond to increasingly multilingual school populations, and face practical challenges in doing so, which can hinder the introduction of more inclusive approaches within schools. EAL services are adapting their service delivery strategies accordingly, but there is still significant progress to be made regarding improving teaching practices and increasing understanding of the benefits of linguistically diverse schools. Contesting negative beliefs about multilingualism and the value of allochthonous languages - both in schools and within families-also continues to be an important task.

This is complicated by stretched resources and growing demand, but the increased focus on training within schools may facilitate the shifting of existing views and shaping of more inclusive school communities. Challenging negative attitudes and promoting the value of a range of allochthonous languages is important given the lack of specific obligations established by instruments such as the Scottish Government's 1+2 Language Strategy. At present, the responses to increased mobility and multi- lingualism do not appear to be entirely inclusive, suggesting that a trade-off between mobility and inclusion has indeed occurred.

\section{Acknowledgements}

The research leading to these results has received funding from the European Community's Seventh Framework Programme under grant agreement no. 613344 (Project MIME). I wish to thank Professor Rob Dunbar for his supervision and support. Certain aspects of this article were discussed as part of my presentation at the Politics of Multilingualism: Possibilities and Challenges conference held in Amsterdam in May 2017 and I would like to thank the conference conveners, Dr Rémi Léger, Dr Christian Noack and Dr László Marácz, for this opportunity. This research benefitted greatly from the interviews carried out with Professor Antonella Sorace, Sandra Scott, Maria Walker and another EAL official, and I thank them for their time. Thanks also to António Vieira from Social Inclusion for his assistance.

\section{Conflict of Interests}

The author declares no conflicts of interest.

\section{References}

Akoğlu, G., \& Yağmur, K. (2016). First-language skills of bilingual Turkish immigrant children growing up in a Dutch submersion context. International Journal of Bilingual Education and Bilingualism, 19(6), 706-721.

Atger, A. F. (2009). Education and political participation of migrants and ethnic minorities in the EU: Policy analysis (CEPS Special Report). Brussels: Centre for European Policy Studies (CEPS).

Baldi, G., \& Wallace Goodman, S. (2015). Migrants into members: Social rights, civic requirements, and citizenship in Western Europe. West European Politics, 38(6), 1152-1173.

Bekers, E. (2009). Chronicling beyond Abyssinia-African writing in Flanders, Belgium. In E. Bekers, S. Helff, \& D. Merolla, (Eds.), Transcultural modernities: Narrating Africa in Europe (pp. 57-69). Amsterdam: Rodopi.

Council of Europe. (2010). Convention for the Protection of Human Rights and Fundamental Freedoms/European Convention on Human Rights (Rome, 4.XI.1950). Strasbourg, France: Council of Europe.

Council of Europe. (2017). Chart of signatures and ratifications of Treaty 177: Protocol No. 12 to the Convention for the Protection of Human Rights and Fundamental Freedoms (ETS No.177). Council of Europe Treaty Office. Retrieved from http://www.coe.int/ en/web/conventions/full-list/-/conventions/treaty/ $177 /$ signatures

Council of the European Union. (1977). Council Directive $77 / 486 / E E C$ of 25 July 1977 on the education of the children of migrant workers. Luxembourg: The Publi- 
cations Office of the European Union.

Council of the European Union. (2008). Council Resolution of 21 November 2008 on a European strategy for multilingualism (2008/C 320/01). Luxembourg: The Publications Office of the European Union.

Dunbar, R. (2007). European traditional linguistic diversity and human rights: A critical assessment of international instruments. In E. Ruiz Vieytez, R. Dunbar, \& K. Villanueva (Eds.), Human rights and diversity: New challenges for plural societies (pp. 85-110). Bilbao, Spain: Humanitarian Net.

Education (Additional Support for Learning) (Scotland) Act 2004. Retrieved from: https://www.legislation. gov.uk/asp/2004/4/contents

Educational Institute of Scotland. (2014). Impact of Glasgow education cuts on schools and most vulnerable must be reviewed. Educational Institute of Scotland. Retrieved from http://www.eis.org.uk

Equality Act 2010 (UK). Retrieved from https://www. legislation.gov.uk/ukpga/2010/15/contents

European Commission. (2008). Green Paper. Migration \& mobility: Challenges and opportunities for EU education systems (SEC(2008) 2173). Brussels: Commission of the European Communities.

European Commission. (2009). Commission staff working document: Results of the consultation on the education of children from a migrant background (SEC(2009) 1115). Brussels: Commission of the European Communities.

Grin, F. (2017). The multilingual challenge: Toward policy responses. February 2017. Mobility and Inclusion in Multilingual Europe (MIME) project. Retrieved from http://www.mime-project.org/MIME_ TheMultilingualChallenge_130216.pdf

Grin, F., Marácz, L., Pokorn, N. K., \& Kraus, P. A. (2014). Mobility and inclusion in multilingual Europe: A position paper on the MIME Project. Paper presented at Mobility and Inclusion in Multilingual Europe (MIME) Kick-Off Conference, University of Geneva.

Hancock, A. (2014). Language education policy in multilingual Scotland: Opportunities, imbalances and debates. Language Problems \& Language Planning, 38(2), 167-191.

Hancock, A. (2017). Heritage language learning in Scotland: A case of linguistic apartheid? Paper presented at Centre for Education for Racial Equality in Scotland (CERES) Conference, Edinburgh, Scotland.

Hansen, R. (2003). Migration to Europe since 1945: Its History and its lessons. The Political Quarterly, 74(1), 25-38.

Human Rights Act 1998 (UK). Retrieved from http://www. legislation.gov.uk/ukpga/1998/42

McLeod, W. (2008). An opportunity avoided? The Eu- ropean Charter for Regional or Minority Languages and UK language policy. In D. Ó Riagáin (Ed.), The European Charter for Regional or Minority Languages: Legal challenges and opportunities (pp. 201-218). Strasbourg: Council of Europe Publishing.

National Association for Language Development in the Curriculum. (2011). National ethnic minority achievement education survey: A summary of findings. October 2011. Retrieved from https://www.naldic.org.uk/ Resources/NALDIC/Advocacy/Documents/NUT\%20N ALDIC\%20SurveyOctober\%202011.pdf

National Association for Language Development in the Curriculum. (2014). The national audit of English as an additional language training and development provision: Report October 2014. Retrieved from https://www.naldic.org.uk/Resources/NALDIC/Rese arch\%20and\%20Information/Documents/NALDIC\%2 0-\%20EAL\%20Audit\%202014\%20FINAL\%20FINAL\%2 OYF\%20Oct\%2014.pdf

National Records of Scotland. (2015). Scotland's Census 2011: Language used at home other than English. Retrieved from http://www.scotlandscensus.gov.uk/ documents/censusresults/release2a/rel2A_Language _detailed_Scotland.pdf

Place, S., \& Hoff, E. (2011). Properties of dual language exposure that influence 2 -year-olds' bilingual proficiency. Child Development, 82(6), 1834-1849.

Scottish Executive. (2010). Supporting children's learning: Code of practice-Revised edition. Edinburgh: Scottish Executive.

Scottish Government. (2010). Statistical Bulletin: Summary Statistics for Schools in Scotland (No.1 2010). Edinburgh: National Statistics.

Scottish Government. (2012). Language Learning in Scotland: A 1+2 Approach. The Scottish Government's Response to the Report of the Languages Working Group. Edinburgh: Scottish Government.

Scottish Government. (2016a). Pupil census 2016 supplementary data. Edinburgh: National Statistics.

Scottish Government. (2016b). Scottish social attitudes survey: Attitudes towards language learning in schools in Scotland. Research Findings, Draft 3/2016. Edinburgh: Scotcen Social Research.

Wang, X. (2011). Learning to read and write in the multilingual family (Vol. 14). Bristol: Multilingual Matters.

Wodak, R., \& Boukala, S. (2015). (Supra)national identity and language: Rethinking national and European migration policies and the linguistic integration of migrants. Annual Review of Applied Linguistics, 35, 253-273.

Wright, S. (2016). Language policy and language planning: From nationalism to globalisation (2nd ed.). Basingstoke, UK: Palgrave Macmillan. 


\section{About the Author}

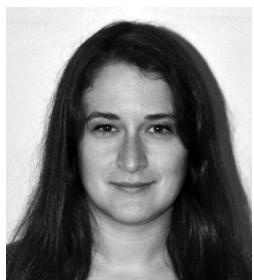

Róisín McKelvey is a PhD candidate in the department of Celtic and Scottish Studies at the University of Edinburgh. Her research interests include language policy (particularly in the context of allochthonous languages), societal attitudes towards multilingualism and the role of language in identity construction. Her PhD research is part of the Mobility and Inclusion in Multilingual Europe (MIME) project and examines provision for allochthonous language speakers within public services in Edinburgh and Glasgow. 